\title{
Estudo de revisão sistemática de Literatura na Educação: Paul Ricoeur em foco
}

\author{
Study of systematic Literature review in Education: Paul Ricoeur in focus \\ Estudio de la revisión sistemática de la Literatura em Educación: Paul Ricoeur en foco
}

Recebido: 11/01/2021 | Revisado: 18/01/2021 | Aceito: 26/01/2021 | Publicado: 02/02/2021

\author{
Mara Regina Rosa Radaelli \\ ORCID: https://orcid.org/0000-0002-5519-2922 \\ Universidade Federal de Santa Maria, Brasil \\ E-mail:maradaelli@gmail.com \\ Fernanda Monteiro Rigue \\ ORCID: https://orcid.org/0000-0003-2403-7513 \\ Universidade Federal de Santa Maria, Brasil \\ E-mail: fernanda_rigue@ hotmail.com
}

\begin{abstract}
Resumo
O presente estudo trata-se de uma Revisão Sistemática de Literatura, no Manancial - Repositório Digital da Universidade Federal de Santa Maria. Possui como propósito identificar as pesquisas em nível de Mestrado e Doutorado que tem como foco as produções e o pensamento do filósofo Paul Ricoeur. Os achados da investigação foram submetidos a tratamento de dados e análise, permitindo identificar suas especificidades no contexto de investigação. Os dados apontam para a pluralidade de possibilidades que o Repositório possui, bem como uma série de publicações que estão vinculadas à ênfase conceitual e de abordagem decorrentes da compreensão de Ricoeur, principalmente no Programa de Pós-graduação em Filosofia, apontando para seu potencial de exploração em demais áreas, como no caso a área da educação.
\end{abstract}

Palavras-chave: Paul Ricoeur; Educação; Revisão sistemática de literatura.

\begin{abstract}
This study is a Systematic Literature Review, at Manancial - Digital Repository of the Federal University of Santa Maria. Its purpose is to identify research at the Master and Doctorate level that focuses on the productions and thinking of the philosopher Paul Ricoeur. The research findings were subjected to treatment of qualitative analysis data, allowing to identify their specificities in the research context. The data points to the plurality of possibilities that the Repository has, as well as a series of publications that are linked to the conceptual and approach emphasis arising from Ricoeur's understanding, mainly in the Postgraduate Program in Philosophy, pointing to its potential for exploration in other areas, such as the education area.
\end{abstract}

Keywords: Paul Ricoeur; Education; Systematic literature review.

\section{Resumen}

Incluir Este estudio es una revisión sistemática de la literatura, en Manancial - Repositorio Digital de la Universidad Federal de Santa Maria. Su propósito es identificar la investigación a nivel de Maestría y Doctorado que se centra en las producciones y el pensamiento del filósofo Paul Ricoeur. Los hallazgos de la investigación fueron sometidos a un tratamiento de datos de análisis, lo que permitió identificarsus especificidades en el contexto de la investigación. Los datos apuntan a la pluralidad de posibilidades que tiene el Repositorio, así como a una serie de publicaciones que se vinculan al énfasis conceptual y de enfoque que surge de la comprensión de Ricoeur, principalmente en el Postgrado en Filosofía, apuntando a su potencial de exploración. en otras áreas, como en el área y la educación.

Palabras clave: Paul Ricoeur; Educación; Revisión sistemática de la literatura.

\section{Introdução}

A permanente busca pela compreensão do modo em que se utiliza de pontos de vista dos pensadores e filósofos que antecederam nosso tempo é uma atividade recorrente nos universos e espaços das diferentes comunidades acadêmicas e científicas. Essa ação é uma possibilidade para perceber os movimentos do presente, sob a orientação e o direcionamento de apontamentos do passado.

Com base nessa assertiva, tendo como eixo norteador o pensamento do filósofo Paul Ricoeur, nos propomos nesse escrito a indagar se existem estudos no contexto da Pós-graduação na Universidade Federal de Santa Maria (UFSM) acerca de 
obras, filosofia e/ou pensamento do referido filósofo. Esse questionamento nos move, pelo fato que durante o segundo semestre do ano de dois mil e dezessete, integramos o Seminário Temático Avançado II do Programa de Pós-graduação em Educação (PPGE/UFSM), promovido pela Linha de Pesquisa 1 (LP1), intitulado 'Memória, Narrativa: Leituras em Paul Ricoeur'.

O referido Seminário Temático Avançado II teve duração de um semestre letivo, o qual propiciou aos discentes de Pós-graduação em Educação da UFSM um direcionamento apurado e minucioso aos escritos construídos por Paul Ricoeur. A leitura assídua das obras do autor permitiu assinalar a linguagem e os pontos de vista do filósofo, o que movimentou a construção de longos períodos de diálogo, reflexão e compreensão do coletivo que deu forma ao mesmo.

Tendo como referência a fluidez e as múltiplas possibilidades oriundas desse Seminário e, interessadas em identificar e compreender se existem/existiram estudos e/ou pesquisas com enfoque no trabalho de Paul Ricoeur no âmbito da UFSM, concebemos pertinente à construção de uma Revisão Sistemática de Literatura (Galvão \& Pereira, 2014) (Sampaio \& Mancini, 2007), no Manancial - Repositório Digital da UFSM ${ }^{1}$. Esta revisão tem como fonte o Banco de Dissertações e Teses (BDTD) apresentadas aos cursos de Mestrado e Doutorado, respectivamente, na UFSM.

Segundo Galvão e Pereira (2014, p. 183) “As revisões que podemos considerar como sistemáticas começaram a aparecer na década de 1950". Para Sampaio e Mancini (2007, p. 85):

Antes de se iniciar uma revisão sistemática, três etapas precisam ser consideradas, quais sejam: definir o objetivo da revisão, identificar a literatura e selecionar os estudos possíveis de serem incluídos. Essas etapas preliminares são importantes, uma vez que auxiliam os pesquisadores a adequar a pergunta norteadora da revisão com base na informação disponível sobre o tema de interesse.

Ao mesmo tempo, as revisões sistemáticas são desenhadas para serem metódicas, explícitas e passíveis de reprodução. Esse tipo de estudo serve para nortear o desenvolvimento de projetos, indicando novos rumos para futuras investigações e identificando quais métodos de pesquisa foram utilizados em uma área (Sampaio \& Mancini, 2007, p. 83).

Nesse sentido, utilizamos o descritor e filtro de título para busca no BDTD: Paul Ricoeur, como refinamento de busca. Debruçamo-nos em verificar a existência de estudos e/ou pesquisas que tem como título/inspiração de estudo o pensamento de Paul Ricoeur. Os achados da revisão do estudo qualitativo (André, 2013) serão submetidos à Análise de Conteúdo (Bardin, 2011), permitindo conhecer, caso houver, os estudos e/ou pesquisas existentes na referida instituição, importante para toda a região sul e o Brasil, o que alarga o leque de horizontes acerca do estudo de Ricoeur, expandindo o compartilhamento de saberes.

\section{Metodologia}

\subsection{O caminhar da Pesquisa}

A partir das forças que nos moveram a definir a importância desse estudo, inicialmente, acessamos a página da UFSM. Nesta página, digitamos na Barra de pesquisa o termo Repositório. Ao abrirem as opções, optamos pelo Manancial Repositório Digital: Página Inicial, conforme apresenta a Figura 1, anexa abaixo:

\footnotetext{
${ }^{1}$ Disponível para acesso no seguinte endereço: http://repositorio.ufsm.br.
} 
Figura 1. Manancial - Página Inicial.

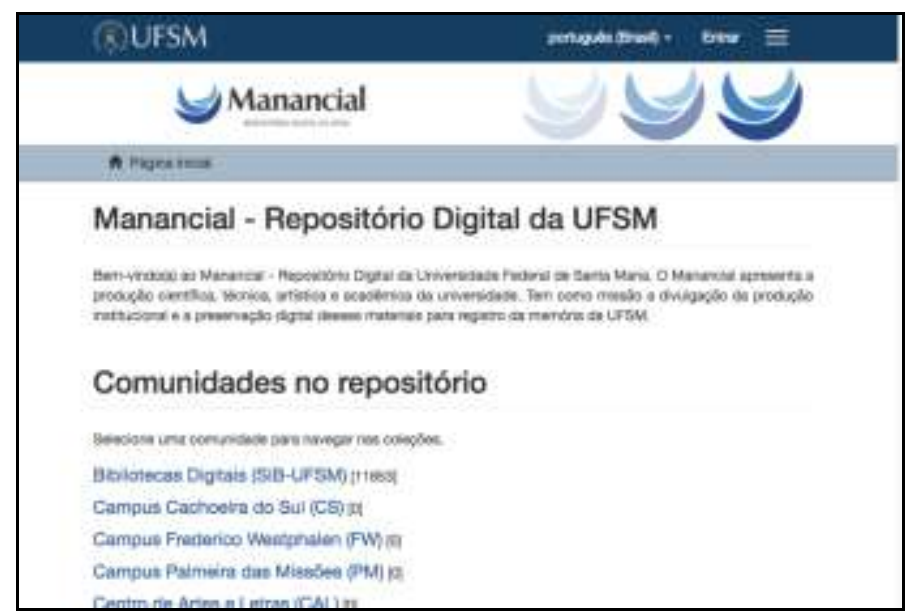

Fonte: http://repositorio.ufsm.br/

Na Página do Manancial - Repositório Digital da UFSM, encontram-se diversas opções de Links de direcionamento para diversas Comunidades no Repositório, conforme apresentou a Figura - 1, o que permite selecionar uma comunidade para navegar. Nesse sentido, optamos por selecionar a Comunidade: Bibliotecas Digitais (SiB-UFSM), que direcionou a pesquisa para próxima página, expressa na Figura 2.

Figura 2. Comunidades no repositório - Bibliotecas Digitais.

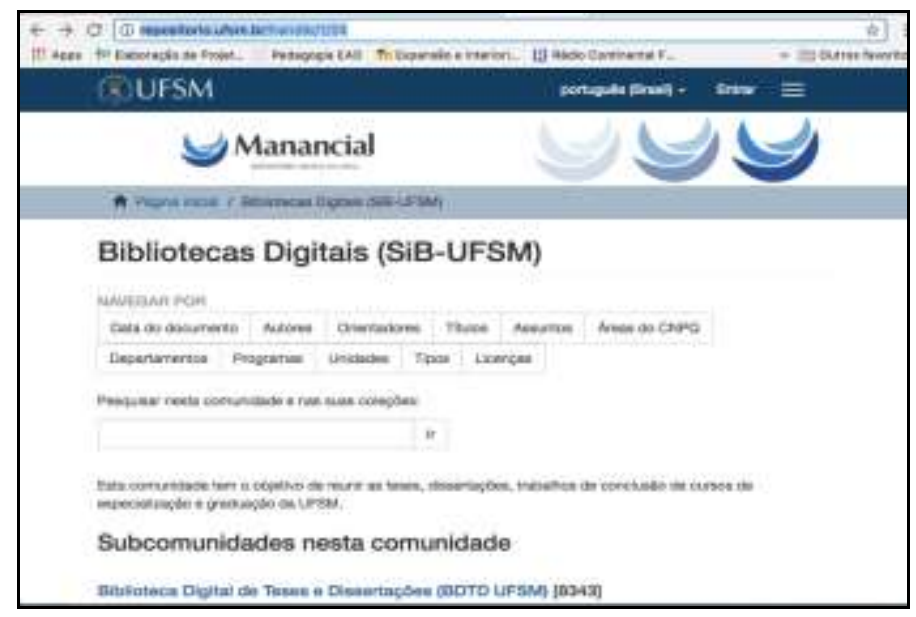

Fonte: http://repositorio.ufsm.br/handle/1/24.

Conforme apresenta a Figura 2, nesta página é possível navegar por diversos Links, tais como, pesquisa por data do documento, por autores, por orientadores, assuntos, entre outros. Nesse sentido, optamos por digitar Paul Ricoeur no campo de pesquisa desta comunidade. E, posteriormente, buscamos a Subcomunidade: Biblioteca de Teses e Dissertações, assim estreitando a pesquisa, conforme demonstrado nas Figuras 3 e 4. 
Figura 3. Subcomunidades da comunidade - Bibliotecas Digitais

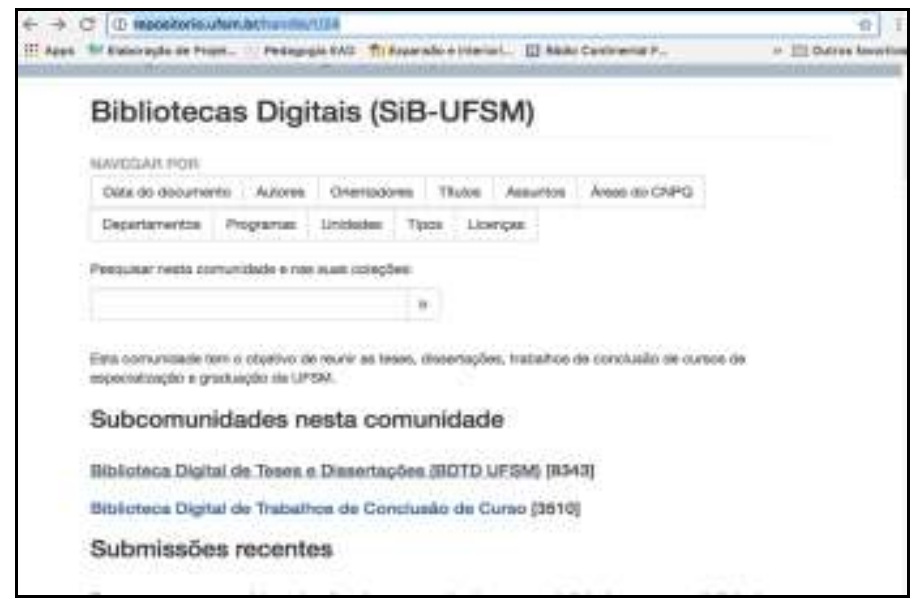

Fonte: http://repositorio.ufsm.br/handle/1/24.

Figura 4. Dissertações de Mestrado.

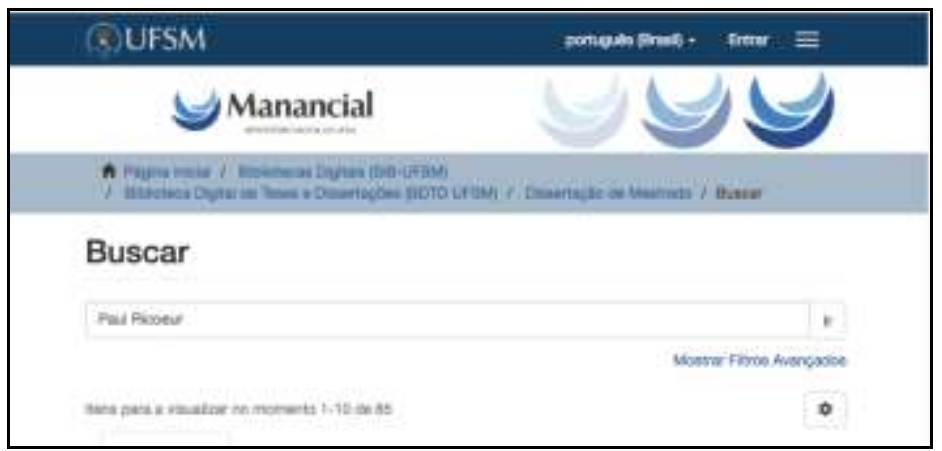

Fonte: http://repositorio.ufsm.br/handle/1/27/discover.

Ao realizar a busca por Paul Ricoeur na Subcomunidade: BDTD/UFSM - Dissertação de Mestrado, com recorte temporal de 2000 até 2020, foram encontrados um total de oitenta e cinco (85) itens. Ao fazer uma breve revisão percebeu-se que muitas das Dissertações traziam apenas citações de Paul Ricoeur, não correspondendo ao objetivo desta pesquisa, que está interessada em estudos e/ou pesquisas que contenham o descritor Paul Ricoeur no título, assim foi preciso adicionar a opção Filtros Avançados. Ao aplicar o filtro avançado no título, a pesquisa apresentou um refinamento e resultou em dezesseis (16) Dissertações sobre Paul Ricoeur, apresentadas em Cursos de Mestrado na UFSM. Posteriormente realizamos o download destas 16 Dissertações, as quais foram lidas, possibilitando coletar os dados de análise.

Ao mesmo tempo, foram realizadas buscas aplicando o mesmo filtro avançado para Teses de Doutorado. Em decorrência disso, encontramos uma (1) Tese de Doutorado. Por sua vez, no decorrer da interatividade e busca, verificamos a existência de outro trabalho desenvolvido sobre o Filósofo, o qual não apareceu no filtro avançado aplicado anteriormente, tendo em vista que no título constava apenas o termo Ricoeur. Após a leitura deste, o consideramos indispensável para construção desse estudo, totalizando assim, duas (2) Teses de Doutorado apresentadas em Programa de Pós-Graduação da UFSM.

A seguir, elencamos os dados coletados das Dissertações e Teses selecionadas para a presente Revisão Sistemática de Literatura: Título da Dissertação; Autor da Dissertação; Classificação, Curso, e Linha de Pesquisa; Orientador; Palavras chave da Pesquisa; Ano de Publicação; Objetivo Geral; Metodologia. Levando isso em conta, na sequência, apresentamos os achados da pesquisa. 
Dentre os estudos selecionados para essa Revisão Sistemática de Literatura, 16 são Dissertações de Mestrado e os outros 2 configuram-se como Teses de Doutorado. Nesse sentido, apresentaremos brevemente, nessa oportunidade, o modo em que se configuraram esses estudos de Pós-graduação, a partir dos resumos e as respectivas palavras-chave.

Para organização e um melhor detalhamento da apresentação dos dados obtidos, optou-se por uma sequência numérica, detalhada na listagem abaixo, acerca dos estudos selecionados:

- Dissertação 1 - Título: O Mal sofrido em Paul Ricoeur;

- Dissertação 2 - Título: Identidade Pessoal em Paul Ricoeur;

- Dissertação 3 - Título: Solicitude e Respeito ao outro em Paul Ricoeur;

- Dissertação 4 - Título: O caráter e a promessa em Paul Ricoeur: Uma perspectiva narrativa;

- Dissertação 5 - Título: Hermenêutica e teoria da ação em si-mesmo como um outro de Paul Ricoeur;

- Dissertação 6 - Título: A interpretação em Paul Ricoeur: Uma discussão para a reformulação da hermenêutica;

- Dissertação 7 - Título: Metáfora e imaginação poética em Paul Ricoeur;

- Dissertação 8 - Título: O conceito de Mal em Paul Ricoeur;

- Dissertação 9 - Título: Interpretação e argumentação: Uma aproximação à leitura de Paul Ricoeur;

- Dissertação 10 - Título: A simbólica do mal na hermenêutica fenomenológica de Paul Ricoeur;

- Dissertação 11 - Título Tempo e eternidade: a leitura do livro XI das confissões de Agostinho por Paul Ricoeur;

- Dissertação 12 - Entre o justo e o legal: Ricoeur e a noção de Justiça;

- Dissertação 13 - O contraste entre intentio e distentio na experiência interna do tempo: Paul Ricoeur e o livro XI das confissões;

- Dissertação 14 - O problema da identidade pessoal em Paul Ricoeur: dimensão ética do ipseidade;

- Dissertação 15 - Psicanálise e hermenêutica em Paul Ricoeur: da suspeita ao sentido, da fantasia ao símbolo;

- Dissertação 16 - Alteridade e reconhecimento mútuo em Ricoeur.

- Tese 1 - Título: O problema da mediação imperfeita em Paul Ricoeur;

- Tese 2 - Título: Da Reciprocidade à mutualidade: A questão da assimetria em Ricoeur.

\subsection{Dissertações de Mestrado - Estudos sobre trabalhos de Paul Ricoeur no âmbito da UFSM}

\section{Dissertação 1}

A primeira Dissertação selecionada intitulada 'O mal sofrido em Paul Ricoeur' de autoria de Adriane da Silva Machado, orientada pelo professor Dr. Noeli Dutra Rossatto, apresentada ao Programa de Pós-graduação em Filosofia teve como palavras-chave da dissertação: mal, mal cometido, mal sofriso, Ricoeur e ética. Apresentada no ano de 2009, a autora realizou um estudo acerca do mal sofrido em Paul Ricoeur, buscando evidenciar a distinção feita pelo autor entre o mal cometido, que é o pecado, e o mal sofrido, que é o sofrimento. Ao mesmo tempo, conceituou o mal em Paul Ricoeur, sendo o mal sofrido aquele que não possui um agente causador, tendo em vista que o sofrimento nos interpela. Como sugestão do trabalho da autora emerge que as formulações acerca do mal são sempre insatisfatórias, sendo necessário resgatar o fundamento do mal mediante uma ética a qual reflita no contexto instituído.

\section{Dissertação 2}

A Dissertação 'Identidade Pessoal em Paul Ricoeur' de Cláudio Reichert do Nascimento, sob orientação do professor Dr. Noeli Dutra Rossatto, apresentada ao Programa de Pós-graduação em Filosofia teve como palavras-chave: Hermenêutica, simesmo, mesmidade, ipseidade, identidade de narrativa. Defendido em 2009, o estudo visou promover a reconstrução do argumento de Ricoeur em torno da identidade pessoal. Inicialmente o autor apresentou a noção primitiva de pessoa enquanto identidade física, bem como psíquica dos corpos, todavia a pessoa permanece aquilo do que falamos, não se designa a si mesma. $\mathrm{O}$ autor ao recorrer à pragmática da linguagem com intuito de que a pessoa possa dizer a si mesma, quando ela diz 'eu' tendo como interlocutor o 'tu' (segunda pessoa do discurso), todavia esse 'eu' pode designar também a qualquer pessoa que diga 'eu'. A partir dos questionamentos: Como expressar uma e única pessoa, quando se diz 'eu'? Ou: Como dizer a si mesmo ao invés de dizer 'eu digo que', um ato de discurso? O autor utiliza da resposta de Ricoeur para movimentá-los, argumentando 
que a pessoa que diz a si mesma (que faz a enunciação), e a pessoa objeto da identificação são a mesma, tendo em vista o triplo ato de inscrição que é realizado pela nomeação da pessoa no registro público.

Nesse sentido, é direcionada a questão a respeito do problema da identidade pessoal, onde Nascimento (2009) trata a identidade por um lado enquanto código genético (idem ou mesmidade), o que acarreta a pergunta: Como expressar a identidade do indivíduo no tempo que não se reduza à mesmidade? Para tal, emerge como responder a questão 'quem' a qual é dizer 'quem é o agente, o autor da ação'. Logo, a pessoa que age é a quem nós atestamos a ação, ou seja, a ação é a possessão daquele que a faz. Ao mesmo tempo, na concepção de Ricoeur dizer 'quem é o autor da ação' trata-se de contar a história de uma vida. Por fim, o autor apresenta a identidade (ipse ou identidade de si mesmo - ipseidade) enquanto identidade narrativa, tratando-se de compor uma história de vida pela atividade de configuração narrativa.

\section{Dissertação 3}

A Dissertação apresentada por Adelson Cheibel Simões, com título 'Solicitude e Respeito ao outro em Paul Ricoeur', no Programa de Pós-graduação em Filosofia, teve como orientador o professor Dr. Noeli Dutra Rossatto. Com as palavraschave: Ética, moral, solicitude, justiça e sabedoria prática, a mesma foi publicada em 2013. O objetivo geral do estudo foi investigar os conceitos de solicitude e de respeito em Paul Ricoeur, o que supõe adentrar em seus escritos acerca da ética e da moral. A distinção feita por Ricoeur sobre a ética mediante conceitos, direcionados a referencial de vida boa e a moral é indispensável. Ao mesmo tempo, o conceito de Aristóteles acerca da amizade enquanto respeito claro de alteridade também é importante, é nesse sentido que recorre ao conceito de solicitude como possibilidade de acolhida do outro.

$\mathrm{Na}$ sequencia, o autor trata de justificar a necessidade da submissão da intensão ética à prova da norma, visto que é nesta ligação entre obrigação e formalismo que este embate se desenrola e, o resultado é que o respeito de si é correlato moral da estima de si, constituindo-se com base nas estruturas correspondentes. O autor conclui que o respeito de si, o qual no plano moral corresponde à de si no plano ético, somente é pleno se significado quanto respeito da norma estiver se expandido com respeito a outrem. Além disso, o autor trata da ideia de justiça, como resultado da ideia de humanidade na pessoa, destacando que o problema da justiça torna o de estabelecer procedimentos equitativos, de modo a assegurar a todos o respeito com as pessoas. Sendo no plano individual justiça como garantia de liberdade, no plano interpessoal é o respeito e, no coletivo uma norma que assegura o bem viver juntos. Nesse sentido, a sabedoria prática emerge como possibilidade para diminuir conflitos, para alcançarmos vida boa, pensando justo e deliberando o bem.

\section{Dissertação 4}

A Dissertação 'O caráter e a promessa em Paul Ricoeur: Uma perspectiva narrativa' de João Batista Botton, foi apresentada ao curso de Mestrado do Programa de Pós-graduação em Filosofia, na Área de Concentração Filosofia Continental e Analítica sob a orientação do professor Dr. Noeli Dutra Rossatto, no ano de 2010. Pautou seu desenvolvimento a partir das seguintes palavras-chave: Hermenêutica; Si-mesmo; Mesmidade; Ipseidade; Identidade narrativa. Com objetivo de reconstruir e discutir a argumentação Ricoeuriana que conduz à formulação do conceito de identidade narrativa. Analisa o debate entre Paul Ricoeur e Derek Parfit acerca da identidade, o qual interessa fazer do problema uma questão sem sentido, delimitando a noção de pessoa em discussões que tem por centralidade sobre identidade. Esse confronto serve de base para extrair um aparato de conceito, onde Ricoeur visa superar o derrocamento do sentido do conceito de identidade. Para isso, o pesquisador optou em delimitar as diferentes formas de permanência no tempo para uma melhor diferenciação entre identidade-idem e identidade-ipse. A relação entre a narratividade e a temporalidade tem destaque quando analisada, tendo como base a hipótese de Ricoeur acerca da narração enquanto possibilidade de articulação e compreensão do homem e a experiência com o tempo. 
Investigando a formulação de Ricoeur acerca do conceito de identidade pessoal e narrativa, permite a esse estudo a compreensão de como ela se forma de modo dialético.

\section{Dissertação 5}

A Dissertação intitulada 'Hermenêutica e teoria da ação em si-mesmo como um outro de Paul Ricoeur', escrita por Élsio José Corá, no ano de 2004, sob orientação do professor Dr. Noeli Dutra Rossatto, foi apresentada ao curso de Mestrado do Programa de Pós-graduação em Filosofia. Teve como objetivo de pesquisa, investigar a hermenêutica e a teoria da ação em si-mesmo como um outro, em Paul Ricoeur. O estudo refere-se aos conceitos de hermenêutica e teoria da ação em Paul Ricoeur. $\mathrm{O}$ autor centraliza sua análise na relação entre a teleologia e a deontologia, onde procura mostrar a tentativa de ancoragem da hermenêutica no método fenomenológico. Assim, argumenta que a consciência atua enquanto uma espécie de tarefa enquanto interpretação dos signos dos símbolos e dos textos.

\section{Dissertação 6}

A Dissertação de autoria de Cristiane Pieterzack, apresentada em 2009 possui o título 'A Interpretação em Paul Ricoeur: Uma discussão para a reformulação da hermenêutica'. Apresentada ao Curso de Mestrado Interinstitucional em Filosofia, do Programa de Pós-graduação em Filosofia, foi orientada pelo professor Dr. Noeli Dutra Rossatto e co-orientadada pelo professor Dr. Aloísio Ruedell. As palavras-chave do estudo são: Linguagem e Crítica. O objetivo da autora esteve pautado em apresentar a proposta de reformulação do projeto hermenêutico desenvolvido por Paul Ricoeur, a partir do debate entre hermenêutica das tradições e a crítica das ideologias.

Inicialmente, trata da origem do conceito de hermenêutica, bem como sua relação com noções de interpretar e compreender. Passando pelas considerações de Gadamer e Habermas, a autora media o diálogo entre razão hermenêutica de Gadamer e, razão crítica de Habermas, apresentando o que Paul Ricoeur traz como possibilidade de uma racionalidade hermenêutico-crítica.

\section{Dissertação 7}

Intitulada 'Metáfora e imaginação poética em Paul Ricoeur', a Dissertação de Vinicius Oliveira Sanfelice apresentada ao Programa de Pós-graduação em Filosofia, no ano de 2014, foi orientada pelo Professor Dr. Marcelo Fabri. O estudo teve por anseio apresentar o desenvolvimento das teorias mimética e imaginativa que Paul Ricoeur formulou, tendo como base o conceito de inovação semântica que está relacionado aos enunciados metafóricos.

O autor definiu como palavras-chave: Ricoeur, Metáfora, Imaginação e Poética. Ademais o estudo procurou reconstruir a fundamentação de Ricoeur acerca da produção de imagens poéticas, bem como a importância prática na redescrição da realidade e na arte, passando pela utopia e pela criatividade. Para tal, Sanfelice (2014) fez referência as disputas em torno da metáfora do conceito e da imaginação, seguida da disputa com Derrida sobre a Tese de Nietzsche.

\section{Dissertação 8}

A Dissertação intitulada 'O conceito de Mal em Paul Ricoeur', foi escrita por Celso Paulo Costa, em 2008, no Mestrado do Programa de Pós-graduação em Filosofia, sob orientação do Professor Dr. Noeli Dutra Rossatto. A Dissertação, por meio de seus objetivos, procurou refletir especificamente sobre o conceito de Mal em Paul Ricoeur, norteando-se pelas seguintes palavras-chave: Mal, Símbolo e Ética.

Inicialmente o estudo passa pela hermenêutica do símbolo por meio interpretação, que para o autor não é imediata. Em seguida, em oposição à teodiéia e à gnose, o autor analisa os mais diversos níveis de compreensão acerca do conceito de 
mal da tradição. Ademais faz referência a pretensão de dar fundamento ao ato de compreender o mal através de mitos, símbolos e narrativas filosóficas. Assim, destaca as tradições cosmológicas e antropológicas as quais, segundo o autor, se complementam quando o simbolismo do mal de origem direciona o homem como autor, receptor e instituidor do próprio mal. Finalmente dá ênfase a necessidade de resgate do fundamento do mal, mediante uma ética reflexiva a partir do que é instituído.

\section{Dissertação 9}

A autora Claudia Aita Tiellet publicou no ano de 2014, a Dissertação intitulada 'Interpretação e argumentação: Uma aproximação à leitura de Paul Ricoeur', apresentada ao Programa de Pós-graduação em Filosofia. Orientada pelo professor Dr. Noeli Dutra Rossatto, as palavras-chave do estudo foram: Interpretação, Argumentação, Ricoeur e Hermenêutica. O objetivo do estudo esteve debruçado em saber como se sustenta a polarização entre as duas teorias, da interpretação e da argumentação, a partir de: Ronald Dworkin e sua Hermenêutica Jurídica e, Robert Alexy e Manuel Atienza e a argumentação jurídica, ao nível do pensamento jurídico e pontuar a proposta de resolução encaminhada pela análise dos mesmos em Ricoeur, à luz de suas teorias do texto, da ação e da história.

Na concepção do estudo de Ricoeur o suposto antagonismo das teorias de interpretação e argumentação, bem como suas insuficiências internas alicerçam a dialética no debate judiciário. Para Ricoeur seriam semelhantes à dialética entre argumentação e interpretação e, a dialética da explicação e compreensão entre o debate jurídico. Além disso, essa semelhança põe fim à incerteza instaurada como processo.

A autora argumenta que uma decisão judicial só é possível quando pode-se argumentar a favor ou contra esta ou aquela interpretação, o que exige a compreensão dos fatos e da norma, atentas a regras de qualquer discurso prático normativo. Nesse sentido, conclui que a tradição hermenêutica filosófica não é muito diferente da hermenêutica jurídica. Outrossim, o mundo que se abre diante da obra (literária ou legal) é o anseio de diferentes metodologias e modos de tratar o texto, onde a compreensão é exigida a partir da dialética apropriada.

\section{Dissertação 10}

A Dissertação intitulada ‘A simbólica do mal na hermenêutica fenomenológica de Paul Ricoeur’ de autoria de Rafael Mafalda Rodrigues, orientada pelo professor Dr. Noeli Dutra Rossatto, apresentada ao Programa de Pós-graduação em Filosofia, teve como palavras-chave da Dissertação: Símbolo, Mito, Hermenêutica, Fenomenologia, Mal e Ricoeur. Apresentada no ano de 2018, buscava "[...] expor a simbólica do mal desenvolvida pelo método hermenêutico e fenomenológico do autor francês Paul Ricoeur “, (Rodrigues, 2018, p. 13). Para tanto delimitou dois enfoques como centro do estudo: o primeiro, seria descrever o método hermenêutico e fenomenológico criado por Ricoeur; o segundo, está na exposição das interpretações que Paul Ricoeur dá em seus trabalhos em relação a “[...] símbolos da confissão religiosa do mal que considera essenciais à mentalidade ocidental, a saber, os símbolos e mitos pertencentes à cultura hebraica, cristã, helênica, e do Oriente Médio antigo" (Rodrigues, 2018, p. 13).

O autor da Dissertação explica que de maneira ligeira será realizada a exploração dos pressupostos filosóficos, que nortearam Ricoeur para a problemática do mal, assim como a fenomenologia de Husserl. Rodrigues (2018), ao escrever sua Dissertação, a faz destacando aspectos em etapas, como a que se preocupa em mostrar ao leitor o período pré-simbólico de Ricoeur. E, em etapa seguinte, já busca explanar de maneira detalhada a transição metodológica da filosofia de Ricoeur para uma hermenêutica fenomenológica. 


\section{Dissertação 11}

A Dissertação 'Tempo e eternidade: a leitura do livro XI das confissões de Agostinho por Paul Ricoeur' de Bruna Natalia Richter, sob orientação do professor Dr. Noeli Dutra Rossatto, apresentada ao Programa de Pós-graduação em Filosofia, apresentou o seguinte conjunto de palavras-chave: Eternidade, Verbo, Narrativa, Ricoeur, Agostinho e Hermenêutica. Defendida em 2018, o estudo tratou da "[...] relação entre tempo e eternidade no Livro XI das Confissões de Agostinho" (Richter, 2018, p.4). A autora destaca o tempo para Agostinho, como sendo uma experiência interna, num movimento da alma, enquanto distensão. Destaca também que a meditação referente ao tempo e, soma-se a discussão sobre a eternidade e criação do mundo. Para Richter, (2018, p.4), sua Dissertação pretende “[...] mostrar que a experiência temporal e a narrativa - da vida ou dos eventos -, formam um círculo que parte do mundo exterior para o interior do ser humano através da reflexão; e assim, pela narrativa, pode-se experimentar a eternidade".

\section{Dissertação 12}

A Dissertação apresentada por Rafael Alves Padilha, com título 'Entre o justo e o legal: Ricoeur e a noção de justiça', no Programa de Pós-graduação em Filosofia, teve como orientador o professor Dr. Noeli Dutra Rossatto. Com as palavraschave: Justiça, Teleologia, Deontologia e Sabedoria Prática, foi publicada em 2012. O objetivo geral do estudo de Padilha foi propor uma reconstrução e uma discussão da argumentação de Paul Ricoeur em torno à noção de justiça. O autor, por meio de diversas discussões, traz uma contextualização de justiça a partir das argumentações de Ricoeur. Destaca a discussão da obra de Rawls, expediente da phronesis com suas raízes em Aristóteles. E, por fim, o autor ressalta que depois do percurso longo o ato de julgar, afinal é executado, sendo assim cada parte do litígio, sendo contemplada com o que é de direito, colaborando assim para o processo e manutenção da paz social.

\section{Dissertação 13}

A Dissertação 'O contraste entre intentio e distentio na experiência interna do tempo: Paul Ricoeur e o livro XI das Confissões' de Bruna Araujo da Luz, foi apresentada ao curso de Mestrado do Programa de Pós-graduação em Filosofia, sob a orientação do professor Dr. Noeli Dutra Rossatto, no ano de 2017. Pautou seu desenvolvimento a partir das seguintes palavraschave: Tempo, Narrativa e Eternidade. A autora aponta que Ricoeur faz uma reconstrução da categoria tempo de Santo Agostinho, Livro XI das Confissões. Que segundo Ricoeur traz nas entrelinhas a comprovação da tese que ser e medida do tempo se resolvem de forma narrativa, diante da dialética da intentio e distentio. Como proposta, segundo autora da dissertação, se pretende reconstruir a interpretação Ricoeuriana do Livro XI das Confissões, bem como, “[...] verificar a amplitude e a validade desta interpretação no que toca ao tratamento de relação entre intentio e distentio" (Luz, 2017, p. 8).

\section{Dissertação 14}

A Dissertação intitulada 'O problema da identidade pessoal em Paul Ricoeur: dimensão ética da ipseidade', escrita por Jeferson Flores Portela da Silva, no ano de 2017, sob orientação do professor Dr. Marcelo Fabri, foi apresentada ao curso de Mestrado do Programa de Pós-graduação em Filosofia. As palavras-chave do estudo são: Si-mesmo, Ética, Mesmidade, Ipseidade e Identidade Pessoal. Teve como objetivo mapear e rediscutir algumas teses das quais Paul Ricoeur trabalha em Soimême comme un autre (1990). O estudo refere-se as problemáticas em Paul Ricoeur, procurando retomar a "[...] noção de simesmo e de identidade pessoal do si, sua dimensão ética e moral atravessada pela permanência no tempo da ipseidade" (Silva, 2017, p. 8).

Inicialmente traz as discussões da exaltação do 'eu' e a sua decadência, uma possibilidade de pensar. Por meio da noção de hermenêutica do si-mesmo, entrando assim o caráter fragmentário do si e atestação, na discussão, mesmo que não tão 
claramente. Como próximo foco, a problemática passa a ser entre a noção de identidade pessoal e identidade narrativa. Trazendo também discussões em torno de mesmidade e ipseidade.

\section{Dissertação 15}

A Dissertação de autoria de Douglas Moisés Pinheiro Carré, defendida no ano de 2017, possui o título 'Psicanálise e hermenêutica em Paul Ricoeur: da suspeita ao sentido, da fantasia ao símbolo'. Apresentada ao Curso de Mestrado em Filosofia, do Programa de Pós-graduação em Filosofia, foi orientada pelo professor Dr. Noeli Dutra Rossatto. As palavraschave do estudo são: Paul Ricouer, Hermenêutica, Psicanálise, Símbolo e Religião. O estudo deu-se com o objetivo de que ao seu final tenham sido abordados alguns textos clássicos de Freud com temas de religião, lendo-os e interpretando-os a partir da dialética de Ricoeur. Na busca de esclarecer como Ricoeur incorpora "[...] crítica da suspeita à hermenêutica da restauração do sentido" (Carré, 2017, p. 8).

\section{Dissertação 16}

Com título ‘Alteridade e reconhecimento mútuo em Ricoeur' a Dissertação de Paulo Gilberto Gubert, apresentada ao Programa de Pós-graduação em Filosofia, no ano de 2012, foi orientada pelo professor Dr. Noeli Dutra Rossatto. O autor definiu como palavras-chave: Ética, Fenomenologia, Alteridade, Reconhecimento Mútuo e Dom. O autor traz inicialmente referência o conceito aristotélico de amizade e, numa segunda concepção, do imperativo categórico Kantiano, e acrescenta que Ricoeur recomenda a sabedoria prática de modo que se tenha equilíbrio entre teleológica e a deontológica. Num segundo momento, o autor baseado em abordagem fenomenológica, foca a polarização inválida em relação ego e alter ego, quando não valoriza a singularidade do outro.

O estudo contextualiza a relação à ética do respeito e a fenomenologia da simpatia, buscando situar o caráter histórico e antropológico da alteridade, "E por fim destaca que a luta, a violência e o desprezo constituem formas de reconhecimento do outro, que negam a alteridade e ocultam o desejo de solidão mediante a sua morte" (Gubert, 2012, p. 6).

\subsection{Teses de Doutorado - Estudos sobre o trabalho de Paul Ricoeur no âmbito da UFSM}

Tese 1

A Tese de Doutorado intitulada 'O problema da mediação imperfeita em Paul Ricoeur' de Adriane da Silva Machado Möbbs apresentada ao Programa de Pós-graduação em Filosofia, também teve como orientador o professor Dr. Noeli Dutra Rossatto. As palavras-chave selecionadas para o estudo foram: Paul Ricoeur, Hegel, dialética, mediação imperfeita e alteridade. No ano de 2015 o estudo fora defendido, tendo como objetivo geral demonstrar que o problema imediato e do mediato, acompanhado de sua contrariedade em aceitar a imediatidade da consciência, conduzem Paul Ricoeur à questão da mediação. Com o estudo sobre a mediação imperfeita em Ricoeur, a autora sustenta a Tese de que o pensamento de Ricoeur se articula com a base da noção de mediação imparcial, parcial e finita, em distinção à mediação de sentido de Hegel, a qual se define em termos absolutos. Com essa sustentação é implicado reconstruir alguns aspectos internos à obra de Paul, os quais a autora qualifica como três tentações de Hegel (a tentação do absoluto no Espírito, na História e no Estado), bem como implica em examinar algumas Teses que prescreve soluções contrárias (Tese da unidade da obra de Ricoeur e, unidade de sua obra em torno do símbolo).

Como consideração, a autora considera que o símbolo, texto e tradução são apenas diferentes formas de renúncia a toda e qualquer forma de mediação total. Resultante do estudo é que a autora assegura que a mediação imperfeita, aberta e fragmentária se mantém numa dialética ininterrupta que articula o si-mesmo com o outro, a identidade com a alteridade. 


\section{Tese 2}

Da reciprocidade à mutualidade: a questão da assimetria em Ricoeur é a Tese de Doutorado defendida por Paulo Gilberto Gubert, no Programa de Pós-graduação em Filosofia. Sob orientação do professor Dr. Noeli Dutra Rossatto, no ano de 2016, a referida Tese teve como palavras-chave: Paul Ricoeur, Ética, Direito, Fenomenologia, Política, Antropologia, Alteridade, Reconhecimento e Assimetria originária. O objetivo geral desse estudo esteve pautado em confirmar a hipótese de que a assimetria da mutualidade contribui decisivamente para assegurar o outro e, simultaneamente, o respeito á intimidade do outro, isto é, o reconhecimento de sua identidade. Para tal, a Tese versa sobre a questão da dissimetria originária de Paul Ricoeur. O autor sustenta a tese de que a precedência da assimetria da mutualidade ante a simetria da reciprocidade envolve, ao mesmo tempo, a alteridade quanto a insubstituibilidade de cada pessoa, através do reconhecimento mútuo.

Com isso, é possível demonstrar que a simetria não deve ser desconsiderada (tendo em vista a constituição ética, da moral e do direito) e, significa considerar a possibilidade da suspensão da luta por reconhecimento, passando, desse modo, a negatividade para positividade, assim a negação não acabe por reduzir o reconhecimento a um desconhecido. Logo, acarreta assegurar que a mutualidade das relações não se dissolva pelo caráter impessoal da lógica da reciprocidade.

\section{Resultados e Discussões}

Ao encerrar a busca no BDTD da UFSM, totalizamos dezoito (18) estudos realizados em Programas de Pós-graduação da referida instituição. Como início da análise e interpretação dos dados obtidos, adotou-se uma representação gráfica, demostrada na Figura 5, que apresenta uma relação entre o número de Dissertações, Teses encontradas e o ano de publicação de cada estudo. Foram encontradas Dissertações e Teses publicadas no intervalo de 2004 - 2018.

Figura 5. Ano de Publicação das Dissertações e Teses.

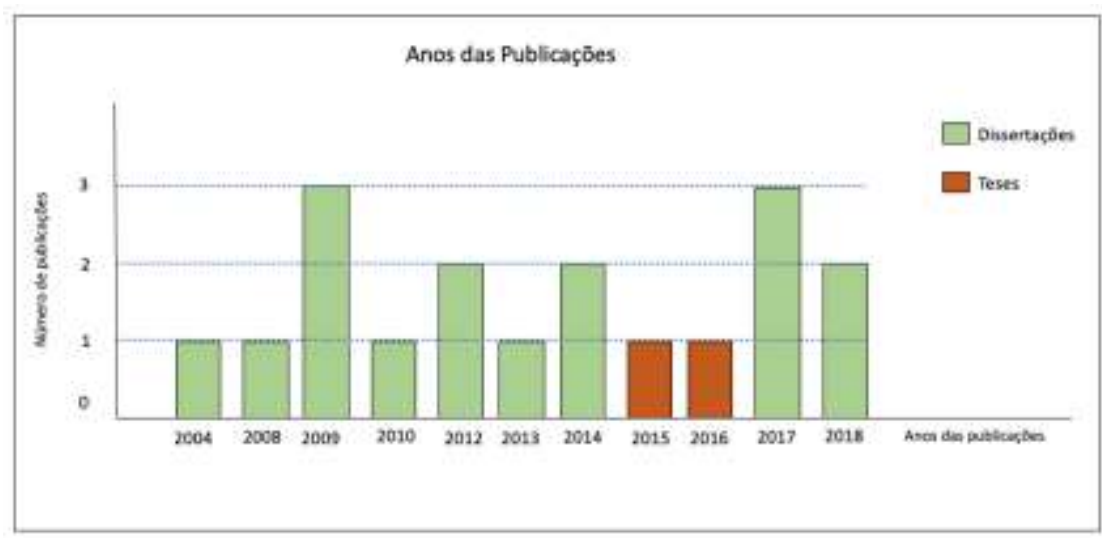

Fonte: Autoras (2021).

Fundamentadas na Revisão Sistemática das 16 Dissertações selecionadas para esse estudo, elencamos por meio de um gráfico apresentado na Figura 6, as palavras-chave presentes nos estudos. 
Figura 6. Palavras-chave das Dissertações.

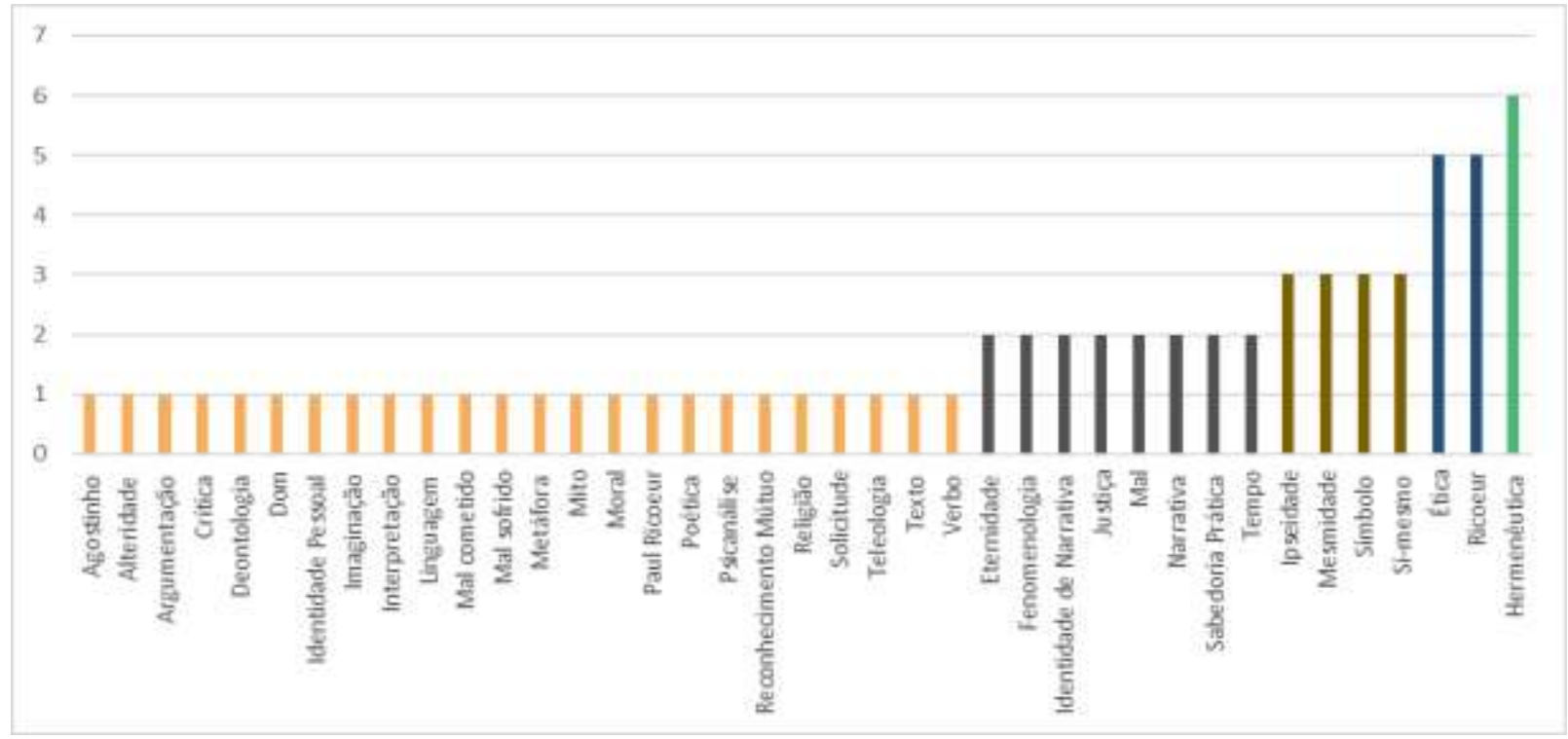

Fonte: Autoras (2021).

Ao mesmo tempo, destacamos graficamente as palavras-chave das Teses selecionadas para esse trabalho, conforme apresenta na Figura 7.

Figura 7. Palavras-chave das Teses.

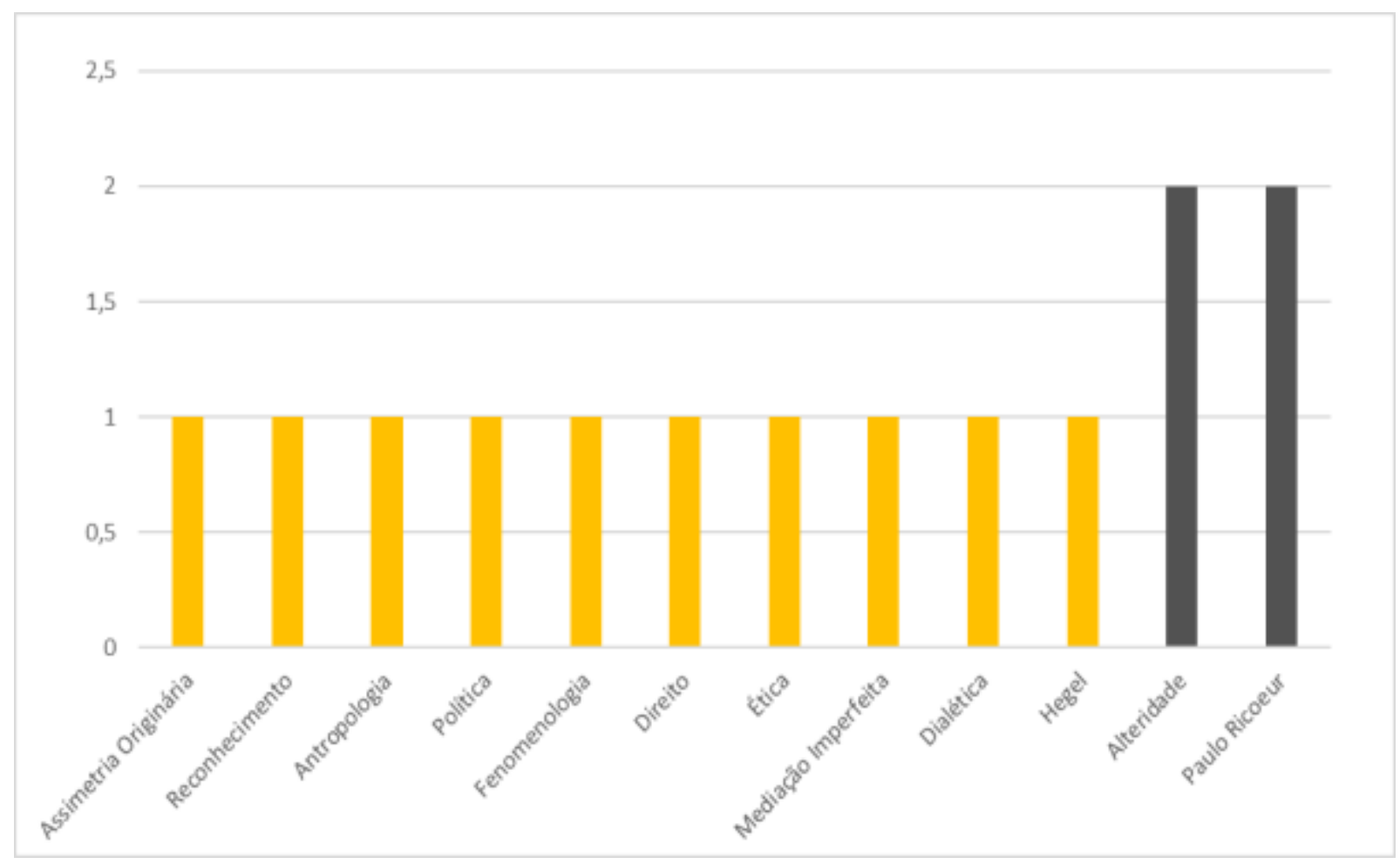

Fonte: Autoras (2021).

Com base no apanhado das palavras-chave dos 18 estudos que tem como foco central Paul Ricoeur, percebemos que muitos foram os conceitos discutidos por esse filósofo que embasaram as investigações sistematizadas nesta pesquisa de revisão. 
Em uma análise dos gráficos apresentados, podemos descrever que no que tange as Dissertações de Mestrado houve um total de 68 palavras-chaves. Entre as palavras elencadas, 24 apareceram apenas uma vez entre as palavras-chave das Dissertações. Observou-se também que 8 palavras-chaves se repetem em duas Dissertações diferentes. Outras 4 palavraschaves são contempladas em 3 Dissertações diferentes. Duas das palavras-chaves aparecem em 5 Dissertações e, apenas uma das palavras-chave se repetiu em um número mais expressivo: a palavra-chave Hermenêutica foi destacada em 6 estudos de Dissertação. Ao mesmo tempo, nas Teses de Doutorado, apenas as palavras-chaves: Paul Ricoeur e Alteridade aparecem mais de uma vez.

Em razão disso consideramos que os estudos possuem uma gama diversa de conceitos e termos explorados ao longo dos estudos apresentados nesta Revisão Sistemática de Literatura.

\section{Considerações Finais}

Ao concluirmos este estudo realizado inicialmente nos meses de novembro e dezembro de 2017 e, revisados em janeiro de 2021 no Manancial - Repositório Digital da UFSM, em relação às Dissertações e Teses que objetivaram desenvolver estudos sobre/com os conceitos do filósofo Paul Ricoeur, podemos destacar dados significativos e potentes que apontam sobre seus desdobramentos em Programas de Pós-graduação da UFSM/RS.

Com base na pesquisa, verificamos a relevância e importância da interatividade do referido Repositório, o que destacamos como ponto positivo para todos aqueles que necessitarem recorrer a pesquisas neste Manancial. Ao mesmo tempo, encontramos diversas opções de Links de direcionamento para diversas Comunidades no Repositório, o que permite ao/a pesquisador/a selecionar uma Comunidade específica de interesse para navegação.

Ao referirmos sobre as Dissertações e Teses encontradas a partir dos filtros utilizados, percebemos que todos os estudos estão concentrados no Programa de Pós-graduação de Filosofia, em diferentes níveis. Onde a maioria significativa foi orientada pelo mesmo professor orientador. Como pontos significantes desse estudo, destacamos a diversidade de conceitos estudados sobre a obra de Paul Ricoeur nas diferentes pesquisas (como apontam as Figuras 6 e 7), apresentando a variedade de especificidades contempladas pelos pesquisadores e pesquisadoras, no que tange o estudo das obras de Paul Ricoeur e sua relação com as investigações. Entre esses conceitos está aquele que aborda a noção de narrativa, conceito que também exploramos no âmbito da disciplina de Pós-graduação em Educação que inspirou o desenvolvimento do presente estudo de Revisão Sistemática de Literatura.

Está aí, na narrativa, um horizonte de possibilidade que pode ser explorado na área de Educação. Na UFSM, a extensão e a tentativa de aprofundamento dos estudos referentes a esse conceito em Paul Ricoeur, já está materializado na área da Educação com o seminário o qual impulsionou a construção desse estudo. O que nos permite considerar, que produções de cunho acadêmico irão emergir, certamente influenciadas por leituras e diálogos que aconteceram no mesmo.

Com isso, ao passo de concluirmos esta série de ponderações acerca do estudo realizado, pretendemos deixar registrado que além dos estudos feitos e aqui elencados, os quais estão cada vez mais crescendo e possibilitando aprendizados, esta pesquisa construída poderá servir como base para referências de futuros estudos, inclusive de Revisão Sistemática de Literatura. E, porque não, como uma espécie de ferramenta que ilustra a realização de busca no Manancial de Dissertações e Teses da UFSM/RS?

\section{Referências}

André, M. E. D. A. de. (2013). Estudo de caso em pesquisa e avaliação educacional. Liber Livros.

Bardin, L. (2011). Análise de conteúdo. Edições 70. 
Botton, J. B. (2010). O Caráter e a Promessa em Paul Ricoeur: uma perspectiva narrativa. 80 f. Dissertação (Mestrado em Filosofia) - Universidade Federal de Santa Maria http://repositorio.ufsm.br/handle/1/9090.

Carré, D. M. P. (2017). Psicanálise e hermenêutica em Paul Ricoeur: da suspeita ao sentido, da fantasia ao símbolo. (Dissertação de Mestrado, Universidade Federal de Santa Maria, Santa Maria, Brasil). http://repositorio.ufsm.br/handle/1/13140.

Corá, É. J. (2004). Hermenêutica e teoria da ação em o si-mesmo como um outro de Paul Ricoeur. (Dissertação de Mestrado, Universidade Federal de Santa Maria, Santa Maria, Brasil). http://repositorio.ufsm.br/handle/1/9159.

Costa, C. P. (2008). O Conceito de Mal em Paul Ricoeur. (Dissertação de Mestrado, Universidade Federal de Santa Maria, Santa Maria, Brasil). http://repositorio.ufsm.br/handle/1/9048.

Galvão, T. F., \& Pereira, M. G. (2014). Revisões sistemáticas da literatura: passos para sua elaboração. Epidemiologia e Serviços de Saúde, 23(1), 183-184. http://scielo.iec.pa.gov.br/scielo.php?script=sci_arttext\&pid=S1679-49742014000100018.

Gubert, P. G. (2012). Alteridade e reconhecimento mútuo em Ricoeur. (Dissertação de Mestrado, Universidade Federal de Santa Maria, Santa Maria, Brasil). http://repositorio.ufsm.br/handle/1/9110.

Luz, B. A. (2017). O contraste entre intentio e distentio na experiência interna do tempo: Paul Ricoeur e o livro XI das Confissões (Dissertação de Mestrado, Universidade Federal de Santa Maria, Santa Maria, Brasil). http://repositorio.ufsm.br/handle/1/14140.

Machado, A. da S. (2009). O Mal Sofrido em Paul Ricoeur. (Dissertação de Mestrado, Universidade Federal de Santa Maria, Santa Maria, Brasil). http://repositorio.ufsm.br/handle/1/9066.

Manancial - Repositório Digital da UFSM. https://repositorio.ufsm.br/.

Möbbs, A. S. M. (2015). O problema da mediação imperfeita em Paul Ricoeur. (Dissertação de Mestrado, Universidade Federal de Santa Maria, Santa Maria, Brasil). http://repositorio.ufsm.br/handle/1/3873.

Nascimento, C. R. do. (2009). Identidade pessoal em Paul Ricoeur. (Dissertação de Mestrado, Universidade Federal de Santa Maria, Santa Maria, Brasil). http://repositorio.ufsm.br/handle/1/9070.

Padilha, R. A. (2012). Entre O Justo e o legal: Ricoeur e a noção de justiça. (Dissertação de Mestrado, Universidade Federal de Santa Maria, Santa Maria, Brasil). http://repositorio.ufsm.br/handle/1/9114.

Pieterzack, C. (2009). A Interpretação em Paul Ricoeur: Uma Discussão para a Reformulação da Hermenêutica. (Dissertação de Mestrado, Universidade Federal de Santa Maria, Santa Maria, Brasil). http://repositorio.ufsm.br/handle/1/9063.

Richter, B. N. (2018). Tempo e eternidade: a leitura do livro XI das confissões de Agostinho por Paul Ricoeur. (Dissertação de Mestrado, Universidade Federal de Santa Maria, Santa Maria, Brasil). http://repositorio.ufsm.br/handle/1/15863.

Rodrigues, R. M. (2018). A simbólica do mal na hermenêutica fenomenológica de Paul Ricoeur. (Dissertação de Mestrado, Universidade Federal de Santa Maria, Santa Maria, Brasil). http://repositorio.ufsm.br/handle/1/15910.

Sampaio, R. F., \& Mancini, M. C. (2007). Estudos de Revisão Sistemática: Um Guia para Síntese Criteriosa da Evidência Científica. Revista Brasileira de Fisioterapia. São Carlos, 11(1),83-89. http://www.scielo.br/scielo.php? script=sci_arttext\&pid=S1413-35552007000100013.

Sanfelice, V. O. (2014). Metáfora e Imaginação Poética em Paul Ricoeur. (Dissertação de Mestrado, Universidade Federal de Santa Maria, Santa Maria, Brasil). http://repositorio.ufsm.br/handle/1/9129.

Silva, J. F. P. (2017). O problema da identidade pessoal em Paul Ricoeur: dimensão ética da ipseidade. (Dissertação de Mestrado, Universidade Federal de Santa Maria, Santa Maria, Brasil). http://repositorio.ufsm.br/handle/1/13070.

Simões, A. C. (2013). Solicitude e Respeito ao Outro em Paul Ricoeur. (Dissertação de Mestrado, Universidade Federal de Santa Maria, Santa Maria, Brasil). http://repositorio.ufsm.br/handle/1/9121.

Tiellet, C. A. (2014). Interpretação e Argumentação: Uma Aproximação à Leitura de Paul Ricoeur. (Dissertação de Mestrado, Universidade Federal de Santa Maria, Santa Maria, Brasil). http://repositorio.ufsm.br/handle/1/9137. 